\title{
O ESPELHO INVERTIDO. REFLEXões SOBRE A RELAÇÃO DO SER HUMANO COM OS OUTROS ANIMAIS
}

Cristina Beckert

(Universidade de Lisboa)

Quando Konrad Lorenz afirma que um dos factores determinantes para a dificuldade do homem se conhecer a si próprio é o modo como percepciona o chimpanzé, está a dar corpo à intenção que presidiu à escolha do título para o presente texto: o espelho invertido ${ }^{1}$. Na verdade, segundo o etólogo alemão, contrariamente ao que aconteceria com outros primatas, como o gorila ou o orangotango, a excessiva proximidade do chimpanzé com o ser humano faz daquele como que uma caricatura deste, uma "perversão" ou "depravação", onde estão salientes todos os traços físicos e psicológicos que queremos rejeitar em nós. Ainda que hoje em dia, depois dos estudos efectuados por Jane Goodall em comunidades de chimpanzés, o retrato do nosso parente mais próximo deva ser substancialmente retocado, estamos em crer que é esta mesma lógica de proximidade e repulsa que preside à relação que o ser humano enceta com todos os animais. Assim se explica que o reflexo especular devolvido pelas outras espécies seja imediatamente invertido e distorcido, de modo a fazer delas o contrário ou o oposto do homem, rejeição essa que vai ao ponto de se traduzir na tentativa de recuperar uma explicação criacionista da origem humana, mesmo depois de Darwin ${ }^{2}$.

${ }^{1}$ Cf. K. Lorenz, A Agressão. Uma História Natural do Mal, trad. I. Tamen, Lisboa, Relógio D'Água, 1992, p. 232.

${ }^{2}$ Um dos mais credíveis defensores do criacionismo é Michael Behe, para quem o evolucionismo darwiniano é válido para provar, por exemplo, a origem comum dos chimpanzés e do homem, mas é insuficiente, na sua visão mecanicista, para explicar a vida molecular. Cf. M. Behe, Darwin's Black Box. The Biochemical Challenge to Evolution, New York, Free Press, 1996.

Philosophica, 40, Lisboa, 2012, pp. 9-23 
Tendo como horizonte hermenêutico este processo de identificação-exclusão, destacaremos alguns momentos privilegiados, ao longo dos tempos, em que é possível surpreender diversos modos de conceber esta relação. O primeiro momento reporta-se aos primórdios da cultura humana, mais propriamente, à visão totémica do mundo, em que o animal eleito como totem é divinizado e, consequentemente, colocado numa posição superior ao homem, servindo-lhe, em simultâneo, de exemplo e de proteç̧ão. Nalgumas representações plásticas do totem, esta relação está bem patente, surgindo o animal em forma gigantesca e o homem diminuto, em posição subalterna, de joelhos flectidos e mãos postas, sinal evidente de submissão. Por outro lado, a qualidade que determina a escolha do animal como totem - seja a força do urso ou a agilidade do macaco - é um factor emblemático que une todos os membros e reforça a relação entre eles, distinguindo-os de outras comunidades vizinhas. Podemos descortinar, por conseguinte, um duplo movimento de identificação ser humano-animal e de exclusão do humano no seio da mesma espécie; por outras palavras, enquanto a divinização de um animal une a comunidade humana, esta, concomitantemente ou não, repudia outros seres humanos do seu seio. Com efeito, "a humanidade cessa nas fronteiras da tribo, do grupo linguístico, e às vezes até da aldeia: a tal ponto que grande número de populações ditas primitivas se designam a si mesmas pelo nome que significa 'os homens' [...], o que implica assim que as outras tribos, grupos ou aldeias não participam das virtudes ou até da natureza humana, antes são, quando muito, compostos de 'maus', de 'malvados', de 'macacos da terra' ou de 'ovos de piolho"'3.

Se nos situarmos, agora, na Grécia Antiga, verificamos que a relação ser humano-outros animais se inverte de forma drástica, passando o homem a ocupar a posição cimeira, ao passo que os animais não-humanos, nomeadamente, os animais domésticos, são relegados para uma posição subalterna de total submissão ao poder humano. No entanto, permanece, como permanecerá até aos nossos dias, a cisão no interior da própria humanidade, sendo a alguns humanos, a saber, aos escravos, atribuído o mesmo estatuto que aos animais domésticos. Nas palavras de Aristóteles:

3 “L'humanité cesse aux frontières de la tribu, du groupe linguistique, parfois même $\mathrm{du}$ village: à tel point qu'un grand nombre de populations dites primitives se désignent elles-mêmes d'un nom qui signifie 'les hommes' [...], impliquant ainsi que les autres tribus, groupes ou villages ne participent pas des vertus ou même de la nature humaine, mais sont tout au plus composés de 'mauvais', de méchants', de 'singes de terre' ou d' 'oeufs de poux'." (A. Finkielkraut, L'Humanité perdue. Essai sur le XXème siècle, Paris, Seuil, 1996, p. 14). 
"O uso que fazemos de escravos e de animais domésticos não é muito diferente; pois ambos, com os seus corpos, satisfazem as necessidades da vida." 4

Como se pode verificar, tanto os animais como os escravos têm valor de uso ou instrumental, na medida em que se destinam a satisfazer as necessidades dos homens livres ou dos cidadãos da pólis, função que partilham também com as mulheres. Estes, por seu turno, gozam do poder que lhes é conferido pelo exercício da actividade racional, sendo a posse da razão um factor diferenciador entre animais e escravos, uma vez que os primeiros, porque não possuem razão, são incapazes de compreender a sua inferioridade, devendo ser obrigados, pela força, a obedecer, ao passo que os escravos são capazes de entender a sua situação e de obedecer sem se tornar necessário o uso da força. A privação da razão tornava-se o fundamento último para o exercício do poder sobre os animais não-humanos, mesmo que a pretensa racionalidade dos homens não se traduzisse senão na utilização do seu contrário, a força bruta. Dá-se, assim, início a uma longa tradição de supremacia moral humana que durou até aos nossos dias, mas onde o especismo ia a par do racismo e do sexismo, prolongando a discriminação no interior da própria humanidade que surpreendemos desde o início.

Curioso é notar que, quanto mais se afirma a supremacia da razão e, por conseguinte, maior é o domínio do ser humano sobre a natureza em geral e os animais em particular, maior é, em simultâneo, a solidão do homem e a consciência da sua pequenês ${ }^{5}$. Este paradoxo afirma-se com toda a veemência na modernidade, quando a subjectividade humana se cinde da natureza e a torna tão-só objecto de conhecimento ou pura extensão indiferenciada e não já uma entidade animada, capaz de servir de exemplo à actividade moral do homem. Esta objectivação do mundo natural resulta, em última instância, do afastamento da figura divina que, no deísmo, deixa de assistir à criação, limitando-se a dar o "primeiro piparote" que põe em movimento as leis da Mecânica subsistentes por si mesmas. Deus é, assim, o grande Engenheiro que o homem deve imitar, justamente pela criação de objectos mecânicos semelhantes aos naturais, dando origem ao processo emancipatório da técnica, emblematicamente expresso na primeira formulação do imperativo técnico, enunciado por Francis Bacon na Nova Atlântida, e que declara ser a nossa finalidade "o conhecimento das causas e do movimento secreto das coisas; e a extensão

\footnotetext{
${ }^{4}$ Aristóteles, Política, I, 1254b 20-30.

${ }^{5}$ É bem conhecida a exclamação de Pascal quanto ao terror que lhe inspira o silêncio dos espaços infinitos. Cf. Pensées, Éd. Lafuma, \& 201.
} 
dos limites do império do homem sobre a natureza inteira para a execução de todas as coisas possíveis"'.

É este poder ilusório do ser humano sobre a natureza que o leva a reduzi-la à sua própria dimensão ou àquilo que ele tem a capacidade de executar, a saber, objectos artificiais. Assim se explicam as conhecidas afirmações de Descartes segundo as quais o mecanismo mediante o qual um relógio marca as horas é tão natural como aquele que faz as árvores produzir frutos, ou ainda, aquele que faz dos animais "autómatos naturais"7. Esta crença na natureza mecânica dos animais que os destitui de sensibilidade, legitimando a vivissecção e outras práticas dolorosas que, hoje em dia, se mostrariam moralmente intoleráveis, permaneceu de tal modo implantada na época que Vaucanson construiu, em 1793, um pato provido de todos os órgãos internos, estando plenamente convicto que "funcionaria" tão bem como qualquer pato natural, não só ao nível da locomoção, como da alimentação e outras funções vitais.

No entanto, se assistimos à máxima degradação no que toca ao estatuto moral dos animais não-humanos, o poder ilimitado do homem não se exerce apenas sobre as outras espécies, mas também sobre si próprio, enquanto ser natural ou res extensa, isto é, corpo. Basta contemplarmos a Lição de anatomia de Rembrandt para compreendermos, de imediato, que o corpo humano passou, também ele, a auferir do estatuto de objecto observável, manipulável, dissecável, como qualquer outro, ao ponto de se ter tornado credível a sua substituição por uma figura mecânica. Foi o que aconteceu com "O turco Mecânico" ou "O autómato jogador de xadrez", construído por Wolfgang von Kempelen para impressionar as cortes europeias, fazendo crer que a figura vestida de turco era capaz de vencer qualquer humano. Embora se trate de uma ilusão, pois o verdadeiro jogador não é o autómato, mas um homem bem real que se encontra escondido no interior da mesa de jogo e que manipula o mecanismo, este exemplo ilustra bem a crise de identidade por que passava o homem ocidental e que permanece ainda hoje ${ }^{8}$.

Estamos, por conseguinte, em face de uma nova forma de exclusão que se reporta, não já apenas a um sector determinado da humanidade,

\footnotetext{
6 "The end of our foundation is the knowledge of causes, and secret motions of things; and the enlarging of the bounds of human empire, to the effecting of all things possible." (F. Bacon, The New Atlantis, Hazleton, PA, The Pennsilvanis State University, 1998, p. 31).

${ }^{7}$ Cf. Descartes, Principes de la Philosophie, IV, \& 203) e Carta a Henry More [5 de Fevereiro de 1649].

${ }^{8}$ Como se verá adiante, o fisicalismo contemporâneo, segundo o qual a consciência é um processo físico que em nada se distingue de um qualquer dispositivo artificial, é o herdeiro desta identificação entre o natural e o artificial.
} 
como anteriormente, mas a uma parte constituinte de todo o homem, aquela que o liga à restante natureza. Assim sendo, a razão passa a ser critério único de humanidade e, ao mesmo tempo, de consideração moral; possuir razão é ser capaz de discernir entre o bem e o mal, ser livre e responsável pelas suas acções, numa palavra, pertencer à comunidade moral humana.

\section{II}

A racionalidade é uma das temáticas que melhor exemplificam o mecanismo do "espelho invertido", pois vemos em outros animais procedimentos que apontam para a posse de razão e invertemo-los em comportamentos instintivos. Com efeito, já no séc. XVII, Locke denunciava o critério racional para distinguir o ser humano dos outros animais, pois, perante um papagaio que fosse dotado de uma razão idêntica à humana $\mathrm{e}$ um homem com um grau de racionalidade semelhante à de um papagaio, não diríamos que o primeiro é um homem e o segundo um animal, mas sim que "[...] um era um homem estúpido e irracional e o outro um papagaio muito inteligente e racional" 9 . Daqui se deduz que não é tanto a razão, mas a forma física, ou seja, o corpo, o verdadeiro critério distintivo entre animais humanos e não-humanos, sendo, a nosso ver, esta passagem de An Essay Concerning Human Understanding, a primeira formulação daquilo que, já no séc. XX, Richard Ryder veio a chamar especismo ou preconceito especista. Por outro lado, um século mais tarde, depois de referir a capacidade de um cão para evitar perigos, afastar estranhos e acariciar o dono, Hume conclui:

"Afirmo que [tais acções] procedem de um raciocínio que, em si mesmo, não é diferente nem fundado em princípios diferentes daquilo que aparece na natureza humana." 10

É evidente que estas palavras devem ser entendidas, no contexto do cepticismo e empirismo humeanos, como crítica a uma razão autónoma em face da experiência, defendendo o autor que toda a inferência a partir de casos anteriores é comum ao ser humano e a outras espécies animais e deriva exclusivamente da experiência. Fica em aberto a hipótese de, caso seja possível provar a existência de uma razão autónoma, nos humanos, se ela se encontra também nos restantes animais.

9 "[...] the one was a dull irrational Man, and the other a very intelligent and rational parrot." (J. Locke, An Essay Concerning Human Understanding, Livro II, cap. 27, \& 8).

10 "I assert they proceed from a reasoning, that is not in itself different, nor founded on different principles, from that which appears in human nature." (D. Hume, $A$ Treatise of Human Nature, Livro I, Parte III, secção XVI). 
A resposta a esta questão surge, já nos anos 70 do séc. $\mathrm{XX}$, com os trabalhos de Donald Griffin no âmbito da Etologia Cognitiva. Reagindo ao behaviourismo dominante na época, introduz nos seus estudos dimensões até então negadas aos animais, a saber, a consciência, a intencionalidade e o pensamento, propondo, simultaneamente, uma alteração metodológica. Em vez do comportamento animal ser estudado em laboratório, deveria antes ser observado em ambiente natural, sob pena de a situação de cativeiro poder criar distorções que viriam a comprometer as conclusões dos trabalhos. Por exemplo, a observação do comportamento de uma gazela-de-Thompson, perante um leão, permitiria afirmar que ela é capaz de identificar o seu predador de diversos ângulos e vendo apenas partes do seu corpo, como a cauda ou a cabeça, o que leva Griffin a concluir ser a gazela possuidora de pensamento abstracto, pois é capaz de elaborar um "conceito" de leão-predador, identificável mesmo que parcialmente visto. ${ }^{11}$ Por sua vez, esta capacidade conceptual tem como suporte a inferência do passado para o presente, a qual não implica apenas o hábito, mas a consciência temporal que une o passado e o presente e que é constitutiva da memória. É por um acto de memória que a gazela une uma experiência passada ao presente, mas é por um acto de pensamento que identifica aquela figura, tão-só vislumbrada, como um predador, desencadeando o comportamento de fuga.

Por outro lado, além da capacidade de abstracção, ou aliada a ela, os animais operam segundo um raciocínio hipotético (se x, então y) observável em cativeiro quando, por exemplo, um rato se apercebe que, carregando num botão luminoso, obtém comida, mas também em ambiente natural, quando a mesma gazela-de-Thompson de há pouco foge do predador (se não fugir, será morta). A partir de 2002, foram realizadas experiências com corvos, pelo Behavioural Ecology Research Group da Universidade de Oxford, que mostram como estes, não só utilizam ferramentas, como são capazes de raciocínio hipotético espontâneo, isto é, não derivado do hábito nem da memória ${ }^{12}$. Em 2006, Betty, um corvo-fêmea a quem foram apresentados um pequeno balde com comida dentro de um tubo de vidro - impossibilitando o acesso directo à comida -, e uma série de arames, pegou num destes com o bico, torceu-o em forma de gancho e introduziu-o no tubo, erguendo o balde pela asa e retirando-o do tubo.

É evidente que estamos perante um mamífero dotado de um sistema nervoso sofisticado e de uma ave, cujo cérebro, embora mais elementar,

${ }^{11}$ Cf. D. Griffin, Animal Minds, Chicago, The University of Chicago Press, 1992, p. 122.

12 Cf. "Tool Manufacture", Behavioural Ecology Research Group, Oxford University, http://users.ox.ac.uk/ kgroup/tools/tool_manufacture.shtml\#references (consultado a 07/08/2012). 
parece dar conta das mesmas funções, mas Griffin pretende ir mais longe e atribuir consciência intencional a animais muito menos complexos como os peixes e, até, os insectos. Assim, a dança das abelhas, mediante a qual estas comunicam entre si, transmitindo informações acerca da localização de alimentos ou de sítios adequados à fundação de novas colmeias, implicaria a consciência daquilo que é transmitido, segundo o princípio de que, se supomos a consciência para haver comunicação, então as abelhas são conscientes ${ }^{13}$. Partindo deste pressuposto, conclui o autor:

"Deveríamos precaver-nos contra o sentimento de que apenas primatas, ou só mamíferos e aves, têm a capacidade de aprender discriminações moderadamente complexas. Pois a vida natural de quase todos os animais activos requer que estes discriminem entre uma larga variedade de objectos e que decidam serem uns comestíveis, outros perigosos e assim por diante." 14

Esta posição está longe de ser consensual. No que se refere aos insectos, outras evidências, nomeadamente ao nível neurofisiológico, apontam em sentido contrário, na medida em que o tamanho extremamente reduzido do cérebro dos insectos e a escassez neural não permitem um controlo integral do organismo, de tal modo que várias extensões do corpo de alguns destes animais não respondem a estímulos dolorosos, o que explica, por exemplo, que possam ser comidos sem deixar de comer em simultâneo. Encontra-se, sim, no caso das formigas, térmitas, abelhas e vespas, uma inteligência social, capaz de organizar as comunidades, não mediante a supervisão de uma qualquer instância exterior, mas pelo impulso que cada indivíduo transmite ao seguinte, por um processo químico baseado em feromonas ${ }^{15}$. No entanto, apenas analogamente se poderá falar de inteligência e de consciência, uma vez que o processo de decisão destes insectos se dá em organismos pouco individualizados e muito dependentes do todo em que se inserem.

13 Griffin defende a existência de comportamentos semelhantes entre insectos e mamíferos, concluindo, no caso das abelhas, que há um pensamento implícito no seu comportamento. Cf., a este propósito, D. Griffin, Animal Minds, pp. 28-30.

14 "We should be on guard against the feeling that only primates, or only mammals and birds, have the capacity for learning moderate complex discriminations. For the mental life of almost any active animal requires it to discriminate among a wide variety of objects and to decide that some are edible, others dangerous and so forth." (D. Griffin, Animal Minds, p. 124).

15 Há mesmo quem defenda que os insectos sociais têm um algoritmo simples para executar tarefas complexas, sendo este último muito útil na resolução de problemas nas telecomunicações. Cf. D. Gordon, Collective Intelligence in Social Insects, http://ai-depot.com/Essay/SocialInsects-Ants.html (consultado a 08/08/2012). 
Julgamos prudente manter um saudável meio-termo entre duas posições radicais: por um lado, o fisicalismo de um Daniel Dennett e, por outro, o que poderíamos designar como o pan-psicologismo de Griffin. Ambos têm em comum a necessidade de esbater fronteiras e distinções hierárquicas, mas fazem-no em sentido inverso. Dennett intenta explicar o fenómeno da consciência e suas modalidades - desejo, crença, intencionalidade - a partir do conceito de postura intencional [intentional stan$c e$, isto é, a intencionalidade cognitiva e desiderativa são posturas explicativas da consciência, tal como a postura final [design stance] explica a vida e a postura fisica [physical stance] explica o mundo dos corpos inanimados, mas, na verdade, não há uma diferença qualitativa entre o movimento de uma pedra atirada, previsível na sua trajectória, o comportamento de uma ave migratória que se dirige para um destino longínquo e um ser humano que deseja o carro desportivo exposto no stand automóvel, indo a previsibilidade diminuindo à medida que o grau de abstracção aumenta; mas nenhuma destas estruturas diverge, também, do software de um computador ou até de um dispositivo menos complexo como o termómetro que faz disparar um termóstato quando a temperatura aumenta ou diminui como se desejasse mais calor ou mais frio ${ }^{16}$. Nas palavras de Dennett, "devemos tratar as entidades ruidosas [gravadores audio] como um agente, mais ainda, como um agente racional que alberga crenças e desejos e outros estados mentais que exibem intencionalidade ou 'acerca de' e cujas acções podem ser explicadas (ou preditas) com base no conteúdo destes estados" 17 .

Facilmente seríamos levados, perante estas declarações, a acusar o autor de antropomorfismo, se não soubéssemos que considera a própria consciência, com as suas crenças, desejos e estados intencionais, como pura ilusão, um truque de magia. Assim sendo, o que existe, realmente, são os sistemas físicos, para os quais se remetem, tanto os sistemas biológicos, como os mentais, humanos ou não. Posto isto, podemos sintetizar o pensamento de Dennett dizendo que, para este último, "tudo o que parece não é", contrariamente ao de Griffin, para quem "tudo o que parece é"; por outras palavras, enquanto o primeiro mantém a estrutura explicativa da consciência em todas as esferas do real, mas esvazia-as de substância, o segundo distingue claramente o plano físico do biológico, mas atribui consciência a todos os níveis da vida, com base na "aparência" de com-

${ }^{16}$ Cf. D. Dennett, The Intentional Stance, Cambridge, MIT Press, 1987, pp. 43-68.

17 "We must treat the noise-entities as an agent, indeed a rational agent, who harbors beliefs and desires and other mental states that exhibit intentionality or 'aboutness' and whose actions can be explained (or predicted) on the basis of the content of these states." (D. Dennett, Consciousness Explained, Toronto et al., Little Brown \& Company, 1991, p. 76). 
portamentos intencionais. Pela nossa parte, como referimos, preferimos manter algumas diferenças no seio dos seres vivos, em particular dos animais, introduzindo uma hierarquia fundada na complexidade do sistema nervoso e nos consequentes graus de consciência.

Uma última palavra para a faculdade, desde Descartes, associada à consciência e à razão: a linguagem. Hoje é sabido que cada espécie animal tem a sua linguagem própria que pode consistir em vocalizações, posturas corporais, complexos sistemas de sonares (algumas baleias como as orcas, golfinhos e morcegos), mas também mutações cromáticas (lulas e chocos). Por outro lado, alguns, os mais próximos de nós, são capazes de comunicar com o ser humano, não através da linguagem falada, pois não possuem aparelho vocal para isso, mas através dos símbolos convencionados para a comunicação dos surdos. É assim que Koko, a bem conhecida gorila, aprendeu cerca de mil sinais e compreende mais de duas mil palavras em inglês, com que comunica com a sua tratadora. No entanto, a descoberta mais recente vai no sentido da aprendizagem, não apenas do significado de palavras, isto é, da semântica, mas da sintaxe, da articulação das palavras em frases. Com efeito, numa experiência levada a cabo pelo Great Ape Trust (Des Moines - Iowa), o bonobo Kenzy executa tarefas que lhe são transmitidas em inglês oral, através de frases completas como, por exemplo, "pega na seringa e dá uma injecção à boneca" ou "pega nas cebolas e põe-nas dentro da cabeça do boneco", mostrando compreender a diferença entre substantivos e verbos, bem como o modo como se relacionam na frase ${ }^{18}$.

\section{III}

Do que foi exposto, resulta uma questão que não podemos iludir: será que pelo menos alguns animais não-humanos são passíveis de consideração ética? E, se sim, quais e porquê?

A nossa recusa em nivelar, por cima ou por baixo, a consciência, a capacidade de raciocínio e a comunicação animais, obriga a reconhecer diferenças entre espécies e, consequentemente, a estabelecer níveis de consideração moral. Por outro lado, estamos em crer que o critério decisivo para a atribuição de valor moral é a consciência, mas há que averiguar o que ela é e se comporta, também ela, graus. Na verdade, muito provavelmente, a razão pela qual há tanta resistência, sobretudo por parte da filosofia, em atribuir consciência aos animais é a confusão da consciência com um tipo particular da mesma, a consciência reflexiva. Esta última parece ser exclusiva do ser humano, pois implica uma reduplica-

${ }^{18}$ Cf. Human Ape, London, vídeo produzido pela National Geographic e Pioneer Productions of London, 2008. 
ção, isto é, uma consciência da própria consciência perceptiva (de um objecto, estado mental, pensamento etc.), pela qual o sujeito se separa de si próprio e reflecte acerca das suas experiências subjectivas, domínio que é vulgarmente identificado com o da própria subjectividade. Porém, isto não significa que alguns animais não-humanos sejam desprovidos de consciência e até de subjectividade, como é o caso dos primatas, que passam no teste do reconhecimento de si ao espelho, identificando a imagem reflectida como imagem de si próprios. Tal indicia que são sujeitos das suas próprias vivências ou que as vivem na primeira pessoa, numa palavra, que são um eu capaz de identificar as suas percepções, sentimentos, emoções, como seus; mas muitos mamíferos que não têm a capacidade de reconhecimento especular possuem memória do passado e expectativas de futuro, permitindo-lhes estabelecer um continuum de experiências e percepções que constituem a sua própria identidade ou, na expressão de Damásio, o seu "eu autobiográfico" 19.

Para alguns, como Tom Regan, ser-se "sujeito da sua própria vida", "no sentido de que a sua experiência de vida corre bem ou mal para eles", independentemente do interesse ou utilidade que possam ter para terceiros, constitui a condição para a posse de direitos morais, isto é, a sua vida, bem-estar, integridade física e psicológica devem ser mantidas intac$\operatorname{tas}^{20}$. Estamos, aqui, perante uma teoria forte dos direitos dos animais, em que o valor inerente de cada um não autoriza que seja cambiável, em nome de um qualquer bem-estar quantitativamente superior, como pretendem alguns utilitaristas.

Com efeito, é sabido o papel decisivo do utilitarismo, desde Jeremy Bentham a Peter Singer, para o desenvolvimento da ética animal, ao considerarem a senciência como critério básico de consideração moral, mas, quando privilegiam o agregado de indivíduos em detrimento de cada um em si mesmo, contabilizando apenas o total de bem-estar e não o individual, permitem a inflicção de dor e sofrimento a alguns animais, em nome de um maior número. Esta postura holista é, assim, incompatível com a atribuição de direitos, não só a animais não-humanos, mas também a humanos, sobrepondo-lhes o princípio da utilidade ${ }^{21}$.

${ }^{19}$ Cf. A. Damásio, O Livro da Consciência. A Construção do Cérebro Consciente, Lisboa, Círculo Leitores, 2010, p. 45.

20 " [...] Individuals are subjects-of-a-life if they have [...] an individual welfare in the sense that their experiential life fares well or ill for them, logically independently of their utility for others and logically independently of their being the object of anyone else's interests." (T. Regan, The Case for Animal Rights, London, Routledge, 1988, p. 243).

21 Já Stuart Mill dedica o último capítulo da sua obra Utilitarianism ao confronto entre os princípios da utilidade e da justiça, concluindo que o primeiro se deve 
Ao invés, Regan argumenta a partir da analogia entre os direitos do que o autor designa como seres humanos não-paradigmáticos ou marginais, nomeadamente, recém-nascidos, crianças, adultos com graves deficiências mentais, e os animais que possuam as mesmas capacidades cognitivas e afectivas, concluindo que "[...] se incluirmos esses humanos marginais na classe de detentores de direitos, também teremos que incluir alguns animais nesta classe" 22 . A resposta ao argumento reganiano vem pela boca de C. Cohen:

"Os direitos são universalmente humanos; surgem num mundo moral humano, numa esfera moral. No mundo humano, os juízos morais estão por toda a parte; é o facto de todos os seres humanos, incluindo os bebés e os senis, serem membros dessa comunidade moral - e não o facto de, enquanto indivíduos, terem ou não certas capacidades específicas ou méritos - que os torna titulares de direitos. Logo, é irrelevante insistir que os animais têm capacidades notáveis, que têm realmente consciência de si ou do futuro, ou que fazem planos e assim por diante." 23

A nosso ver, este texto não constitui um contra-argumento, mas uma defesa intransigente e dogmática do preconceito especista, em que a primazia da espécie humana surge mascarada de "comunidade moral" ou "esfera moral". Com efeito, é tão-só por pertencerem à espécie homo sapiens que bebés e senis têm direitos, enquanto animais com capacidades porventura maiores são excluídos da comunidade moral. Em última instância, trata-se de um não-argumento, na medida em que se funda em critérios que não são morais, mas meramente fácticos, não respondendo à questão: que características deve ter uma entidade para que lhe sejam atribuídos direitos? Claro que Cohen responderia que a questão está mal posta e que não estão em causa capacidades individuais, mas a simples pertença à tal "comunidade ética", indefinível em si mesma, mas apenas pela espécie. No entanto, poderia ser acusado, por sua vez, de incorrer numa falácia naturalista, mostrando-se o facto escolhido como critério moral, tão arbitrário como o foi, ao longo da história da cultura ocidental, a raça ou o sexo ${ }^{24}$.

sobrepor ao segundo, sempre que o bem-estar do todo esteja em causa, isto é, os direitos individuais não são absolutos, mas violáveis, se a felicidade do maior número assim o exigir.

22 "[...] if we include those marginal humans in the class of rights holders, we must also include some animals in this class." (T. Regan, All that Dwell Therein, Berkeley et al., University of California Press, 1982, p. 123).

${ }^{23}$ C. Cohen, "Os animais têm direitos?" in Os animais têm direitos? Perspectivas e argumentos, org. P. Galvão, Lisboa, Dinalivro, 2011, p. 74.

${ }^{24}$ Estamos perante aquilo que R. Ryder apelidou de preconceito especista e que, 
A verdade é que, pelo menos no que toca aos animais domésticos, vivemos numa "comunidade mista", no dizer de Mary Migdley, em que a senciência, a afectividade e as capacidades cognitivas dos animais são valorizadas, quer no sentido positivo quer negativo. Desde sempre, os homens possuíram animais de estimação pelos quais sentiam e sentem afeição ou ódio, por vezes ambos em simultâneo, mas nunca indiferença $^{25}$. Infelizmente, hoje em dia a indiferença em relação ao destino cruel de milhões de animais criados para consumo humano instala-se cada vez mais, a par de uma crescente preocupação e cuidado por aqueles que nos fazem companhia. O paradoxo desta postura atinge o seu auge quando é a mesma espécie de que cuidamos e na qual investimos afectivamente e que servimos à mesa, como é o caso do coelho.

Esta pertença à mesma comunidade, bem como os abusos que nela têm sido perpetrados contra os animais, fazem com que estejamos em face de uma situação que exige justiça. Martha Nussbaum procura, precisamente, completar a teoria da justiça de John Rawls, dirigindo a sua atenção para aqueles casos que não são chamados a participar no contrato social, visto situarem-se na "fronteira da justiça": os deficientes, os membros de outras nações e os animais. A estes últimos é aplicada a teoria das capacidades, baseada na ética aristotélica e cujo papel a autora define do seguinte modo: "A abordagem das capacidades [...] exorta à avaliação dos poderes básicos de uma criatura, perguntando quais deles têm uma importância central para o seu bem"26.

Está, assim, suposto que cada espécie tem capacidades próprias para o exercício de determinadas funções que, se não forem postas em prática, põem em causa o bem do animal, isto é, o seu pleno desenvolvimento ou o seu florescimento [flourishing], realizando o fim que lhe é próprio, na linguagem de Aristóteles. Num exemplo de Nussbaum, dado que uma das capacidades dos leões é a predação e esta não pode ser exercida em cativei-

desde então, é utilizado como o ponto de partida para a argumentação dos defensores da Ética Animal, mas que estava já presente no conhecido texto de J. Bentham que recusa critérios como a cor da pele ou a morfologia, a razão e a linguagem como critérios de consideração moral. Cf. J. Bentham, The Principles of Morals and Legislation, cap. XVII, secção 1. Para o termo especismo, cf. R. Ryder, Victims of Science. The Use of Animals in Research, National Anti-Vivisection Society, London, $1983^{2}$, p. 5.

${ }^{25}$ Para a relação entre o ser humano e os restantes animais e o conceito de "comunidade mista", cf. M. Migdley, Animals and why they matter, Athens, University of Georgia Press, 1983, cap. 10.

26 "The capabilities approach [...] urges evaluation of the basic powers of a creature, asking which ones are of central importance for its good." (M. Nussbaum, Frontiers of Justice: Disability, Nationality, Species Membership, Cambridge et al., The Belknap Press of Harvard University Press, 2006, p. 94). 
ro, então, os jardins zoológicos devem providenciar para que estes animais tenham acesso a objectos semelhantes em dimensão e peso a uma gazela, a fim de realizarem a sua capacidade predatória. Perguntar-se-á se os leões não exerceriam muito melhor esta função no seu habitat natural, permanecendo em cativeiro apenas aqueles que já não se adaptariam à vida em liberdade. De qualquer modo, a teoria das capacidades supõe uma hierarquia em que o ser humano surge no topo e, por outro lado, o conceito de bem inerente a cada espécie e indivíduo é ambíguo: ou se trata do bem-estar defendido pelo utilitarismo, que, por sua vez, é criticado pela autora como demasiado pobre e restrito ao prazer e à dor físicos, ou está dependente da investigação comportamental realizada no âmbito da Etologia, podendo revelar-se uma imposição do ser humano sobre as restantes espécies ${ }^{27}$.

Até aqui, ocupámo-nos somente dos animais "sujeitos de uma vida", isto é, daqueles que, pela sofisticação do seu sistema nervoso, possuem uma identidade ao longo do tempo, um eu a quem são atribuídos direitos. Porém, existem outras espécies dotadas de um sistema nervoso menos complexo, mas que não deixam de possuir alguma forma de consciência, na exacta medida em que são sencientes. Autores, como Tom Regan, dão o "benefício da dúvida", devido à falta de informação científica sobre estas espécies; outros, na linha utilitarista de Peter Singer, procuram justificar um tratamento diverso, baseado na inexistência de uma consciência de si, mas tão-só de uma consciência. Esta consciência representaria a outra face da senciência, sendo possível afirmar que toda a entidade consciente é senciente e vice-versa, toda a entidade senciente é consciente. Quando, por exemplo, um peixe recebe o estímulo de dor provocado pelo anzol, este "acorda" uma consciência que faz com que o animal se aperceba da dor ou a sinta, embora, porventura, não se distinga a si mesmo da dor sentida. No entanto, esta não é ainda consciência de si plena, na medida em que não implica continuidade temporal, mas um aglomerado de sensações autónomas e pontuais que não constituem uma unidade subjectiva ao longo do tempo. Consequentemente, como afirma Peter Singer,

"Se os peixes fossem mortos enquanto estão inconscientes, [...] não haveria, na perspectiva da consciência dos peixes, qualquer diferença entre isso e os mesmos peixes quando perdem e retomam consciência." 28

27 Para a crítica de Nussbaum ao utilitarismo de Singer e a resposta deste, cf., respectivamente, M. Nussbaum, 'Justice for Non-Human Animals', The Tanner Lecture on Human Values, November 13, 2002 e P. Singer, "A Response to Martha Nusbaum”, http://www.utilitarian.net/singer/by/20021113.htm (consultado a 11/08/2012).

28 "If the fish were killed while unconscious [...] there would, from the perspective 
O caso dos peixes é particularmente importante, na medida em que são consumidos biliões de exemplares em todo o mundo e Portugal, em particular, é o país que consome mais peixe per capita na Europa. De facto, além de serem vertebrados e possuírem um sistema nervoso central, está cada vez mais consolidado, cientificamente, que estes animais têm nociceptores e são capazes de experienciar ansiedade e medo, sofrendo tanto destas experiências como da dor física provocada pelo anzol ou pela sufocação. ${ }^{29} \mathrm{~A}$ distância que nos separa dos peixes, tanto espacial como morfológica, levou a que fossem sistematicamente ignoradas as suas necessidades e bem-estar, embora a crescente produção em viveiros permita testemunhar que, quanto melhores forem as condições que lhes são dadas, em termos de espaço e alimentação, mais se reproduzem. Por tudo isto, julgamos que, embora não lhes devam ser atribuídos direitos, pelo menos no estado actual da investigação científica, é notório que são susceptíveis de bem-estar, o que, em termos práticos, se traduz na condenação moral da pesca. No que toca aos invertebrados, excepção feita aos cefalópodes, não merecem a nossa consideração moral, uma vez mais, nas condições presentes da investigação científica.

As descobertas recentes, na área da fisiologia e do comportamento animal, conduzem à percepção, cada vez mais clara, de que a relação que nós, humanos, encetamos com as outras espécies animais, deve ser pautada por princípios éticos que corroborem aquilo que muitos já experimentam no plano afectivo, a saber, a comunhão de emoções, desejos, anseios e comportamentos, os quais justificam a sua pertença à comunidade ética. Tal pertença, por sua vez, só pode estabelecer-se em termos de um meio-termo entre um antropocentrismo dogmático e um antropomorfismo descabido que ignora as necessidades e as características próprias de cada espécie.

Porém, continuam a ser os outros animais que não deixam de nos surpreender e de nos dar "lições de moral", ao franquear as barreiras da espécie. Um hipopótamo que perde a progenitora num cataclismo ambiental e é adoptado por uma tartaruga gigante; uma leoa que cuida de uma

of fishy awareness, be no difference between that and the same fish losing and regaining consciousness." (P. Singer, Practical Ethics, Cambridge et al., Cambridge University Press, $1992^{2}$, p.126). Embora a posição de Singer seja permissiva no que toca à possibilidade de matar peixes, tal só se verifica do ponto de vista teórico, pois é praticamente impossível matar grande quantidade destes animais sem inflicção de dor e sofrimento.

${ }^{29}$ Cf. G. Franzione, Introduction to Animal Rights. Your Child or the Dog?, Philadelphia, Temple University Press, 2000, p. 21 e M. Bekoff, "Aquatic Animals, Cognitive Ethology, and Ethics: Questions about Sentience and other Troubling Issues that Lurk in Turbid Water", Diseases of Aquatic Organisms, 75(2007), Maio, pp. 87-98. 
gazela recém-nascida, vinda à luz no exacto momento em que a fêmea é morta pela mesma leoa; uma cadela, Ginny, que percorre incansavelmente as ruas de Nova Iorque, recolhendo gatos feridos e trazendo-os ao dono a fim de serem tratados. Estes e outros mais são exemplos de compaixão animal que indicia a existência de uma ética dos animais e não apenas de uma ética para os animais, da nossa exclusiva responsabilidade. 